\title{
A Study on Monitoring and Focussing of Adverse Drug Reactions Caused By Allopathic Medicines in a Tertiary Care Hospital
}

\section{Firoz Khan*, Saurabh Nimesh and Tinku Kumar \\ Department of Pharmacology, Subharti Medical College, Meerut, India}

*Corresponding author: Firoz Khan, M. Pharm (Pharmacology), Research Scholar, Department of Pharmacology, Netaji Subhash Chandra Bose Subharti Medical College, Subhartipuram NH-58, Delhi Haridwar Bypass Road, Meerut, Uttar Pradesh, Pin- 250005, India, Tel: 91-9012537941; Email: fkpharmacy@gmail.com

\section{Abstract}

Adverse drug reaction is the major part of the all the medicines available just like two sides of the coin. On one side the medicines are most prestige for human health but if we focus on another side there are lots of side effects and misuse happens by this prestige drug. In a hospital there are some ADRs are reported but most of them are unreported due to not enough awareness of Pharmacovigilance Programme of India (PvPI). This programme helps to report every single individual including with doctors, nurses, pathologist, pharmacist, medical representative and other life sciences or non life sciences persons to report the adverse effect of the medication. In this case report the ADRs were monitored under the supervision of Subharti Medical College and Hospital, Meerut. All the happened ADR shall be treated under the supervision of professional doctors and reported. So, it was very tough to say, whose drug ready for produce adverse effect. Now, Adverse Drug Reactions are a global health problem and a leading cause of death, illness and injury in economically developed countries. The objective of this study was to identify the possible ways to improve the quality of the ADR reporting with a special focus on improving the aspect of ADR reporting that has to do with symptoms descriptions.

Keywords: Adverse Drug Reaction; Causality Assessment; Antibiotics

\section{Introduction}

World health organization (2004) defines pharmacovigilance as the 'science and activities relating to the detection, assessment, understanding, and prevention of adverse drug reactions (ADRs), or any other medicine-related problems'. ADR is considered to be the $6^{\text {th }}$ leading cause of death. The incidence rate estimates approximately $2 \%$ of hospital admissions are due to ADRs. Drug attributed deaths are estimated to be $0.17 \%$ in all medical inpatients. About $0.40 \%$ of ADRs identified were directly linked to high costs. ADRs not only increase the mortality and morbidity but also multiply the health care cost. ADR monitoring is primarily essential for drugs 


\section{Advances in Pharmacology and Clinical Trials}

with narrow therapeutic index [1]. Respiratory disease causes an immense worldwide health burden. Accordingly to Forum of International Respiratory Societies respiratory disease has a substantial impact on the health of populations at all ages and every level of morbidity [2]. It is estimated that 235 million people suffer from asthma, more than 200 million people have chronic obstructive pulmonary disease (COPD), 65 million endure moderate-to-severe COPD, 1-6\% of the adult population (more than 100 million people) experience sleep disordered breathing, 8.7 million people develop tuberculosis (TB) annually, millions live with pulmonary hypertension and more than 50 million people struggle with occupational lung diseases, totalling more than 1 billion persons suffering from chronic respiratory conditions [3]. At least 2 billion people are exposed to the toxic effects of biomass fuel consumption, 1 billion are exposed to outdoor air pollution and 1 billion are exposed to tobacco smoke. Each year, 4 million people die prematurely from chronic respiratory disease. Infants and young children are particularly susceptible [4]. 9 million children under 5 years of age die annually and lung diseases are the most common causes of these deaths. Pneumonia is the world's leading killer of young children. Asthma is the most common chronic disease, affecting about $14 \%$ of children globally and rising. COPD is the $4^{\text {th }}$ leading cause of death worldwide and the numbers are growing. The most common lethal cancer in the world is lung cancer, which kills more than 1.4 million people each year, and the numbers are growing [5]. Respiratory tract infections caused by influenza kill $250000-500000$ people and cost 71-167 billion US dollars annually. Respiratory infections are ranked as the greatest single contributor to the overall burden of disease in the world, as measured in disability-adjusted life-years lost, which estimate the amount of active and productive life lost due to a condition [6]. Healthcare costs for respiratory diseases are an increasing burden on the economies of all countries. For example, the annual cost of asthma in the USA is estimated to be $\$ 18$ billion. If one considers the lost productivity of family members and others caring for these individuals, the cost to society is far greater. Eight respiratory conditions account for a great burden to society [7]. These are described in above-

- Asthma

- COPD

- Cystic Fibrosis

- Pneumonia and Influenza
- Lung Cancer

- Occupational Lung Disease

- Obstructive Sleep Apnoea

- Tuberculosis

\section{Methodology}

The present study was conducted in the department of respiratory medicine ward of Chhatrapati Shivaji Subharti Hospital (Meerut). It is a 1038 bedded tertiary care teaching hospital in rural area. This PV study has been approved by the Institutional Ethics Committee. All the patients visiting the pulmonary medicine (IPD \& RICU) department who were taking respiratory treatment was included in the study. This is a prospective exploratory open label study design. The patients were treated by consultants in pulmonary medicine and data of these patients was recorded. Patient demographic profile, characteristics, outcome and adverse effects were recorded. The ADRs were recorded in the specify perform a designed by the National Pharmacovigilance Programme for this purpose. All suspected ADRs were recorded with the help of different investigational tests that was depending on the type of ADR. Laboratory investigations were done in appropriate cases. Dechallenge and re-challenge were done if permitted by physician in charge of patient. The patient was followed up till the study completed and any new change in prescription and status of each ADR were recorded.

\section{Case Reports of Patients}

\begin{tabular}{|c|c|c|c|}
\hline \multicolumn{2}{|c|}{$\begin{array}{l}\text { Socio-Demographic } \\
\text { Characteristic }\end{array}$} & $\begin{array}{c}\text { Number } \\
\text { (n) }\end{array}$ & $\begin{array}{c}\text { Percentage } \\
(\%)\end{array}$ \\
\hline \multirow{3}{*}{ Age (in years) } & $15-35$ & 24 & 18.4 \\
\hline & $36-55$ & 34 & 26.2 \\
\hline & $>55$ & 72 & 55.3 \\
\hline \multirow{2}{*}{ Gender } & Female & 49 & 37.6 \\
\hline & Male & 81 & 62.3 \\
\hline \multirow{2}{*}{ Race/area } & Urban area & 54 & 41.5 \\
\hline & Rural area & 76 & 58.4 \\
\hline \multirow{4}{*}{$\begin{array}{c}\text { Smoking/ alcohol } \\
\text { use }\end{array}$} & Smoker & 62 & 47.6 \\
\hline & Alcoholic & 27 & 20.8 \\
\hline & $\begin{array}{l}\text { Alcoholic + } \\
\text { smokers }\end{array}$ & 19 & 14.6 \\
\hline & Other & 22 & 16.9 \\
\hline
\end{tabular}

Table 1: Patients distribution according to sociodemographic and lifestyle-habits. 


\section{Advances in Pharmacology and Clinical Trials}

\begin{tabular}{|l|l|c|c|}
\hline & \multicolumn{1}{|c|}{ Organ system } & Number (n) & Percentage (\%) \\
\hline \multirow{5}{*}{ Type of ADRs } & Skin & 27 & 20.7 \\
\cline { 2 - 4 } & Gastrointestinal & 22 & 16.9 \\
\cline { 2 - 4 } & Central nervous system & 29 & 22.3 \\
\cline { 2 - 4 } & Cardiovascular & 11 & 8.4 \\
\cline { 2 - 4 } & Eyes, ears, nose, and throat & 5 & 3.9 \\
\cline { 2 - 3 } & Hepatotoxicity & 7 & 5.3 \\
\cline { 2 - 4 } & General disorder (Fever, dehydration, pain and swelling at \\
& injection site, taste or smell disturbance) & \multirow{2}{*}{6.2} \\
\cline { 2 - 4 } & Musculoskeletal & 8 & 9.3 \\
\cline { 2 - 4 } & Respiratory & 12 & 6.9 \\
\hline & Add on treatment/drug dose not changed & 9 & 10.8 \\
\cline { 2 - 4 } & Drug withdrawn/stopped & 14 & 66.9 \\
\cline { 2 - 4 } & Dose reduced & 18 & 13.8 \\
\cline { 2 - 4 } & Frequency reduced & 11 & 8.4 \\
\hline
\end{tabular}

Table 2: Type of adverse drug reactions and management.

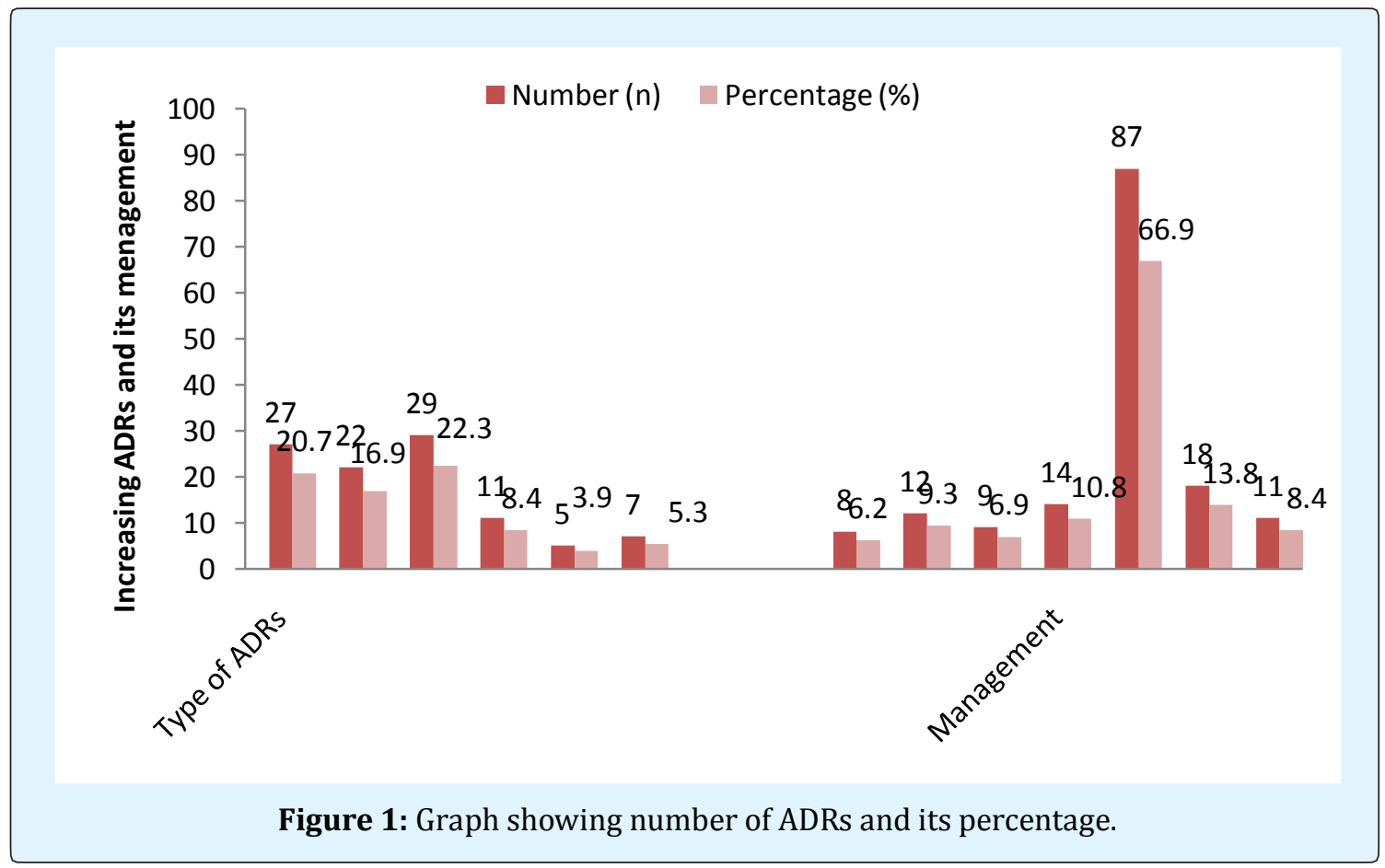

\begin{tabular}{|c|c|c|}
\hline Assessment & Number (n) & Percentage (\%) \\
\hline Certain & 0 & 0 \\
\hline Probable & 69 & 53 \\
\hline Possible & 56 & 43 \\
\hline Unlikely & 5 & 3.9 \\
\hline
\end{tabular}

\begin{tabular}{|c|c|c|}
\hline Severity & Number (n) & Percentage (\%) \\
\hline Mild & 81 & 62.3 \\
\hline Moderate & 47 & 36.1 \\
\hline Severe & 2 & 1.5 \\
\hline
\end{tabular}

Table 3: Causality assessment of ADRs according to

Table 4: Severity assessment of ADRs according to WHO-UMC scale. 


\section{Advances in Pharmacology and Clinical Trials}
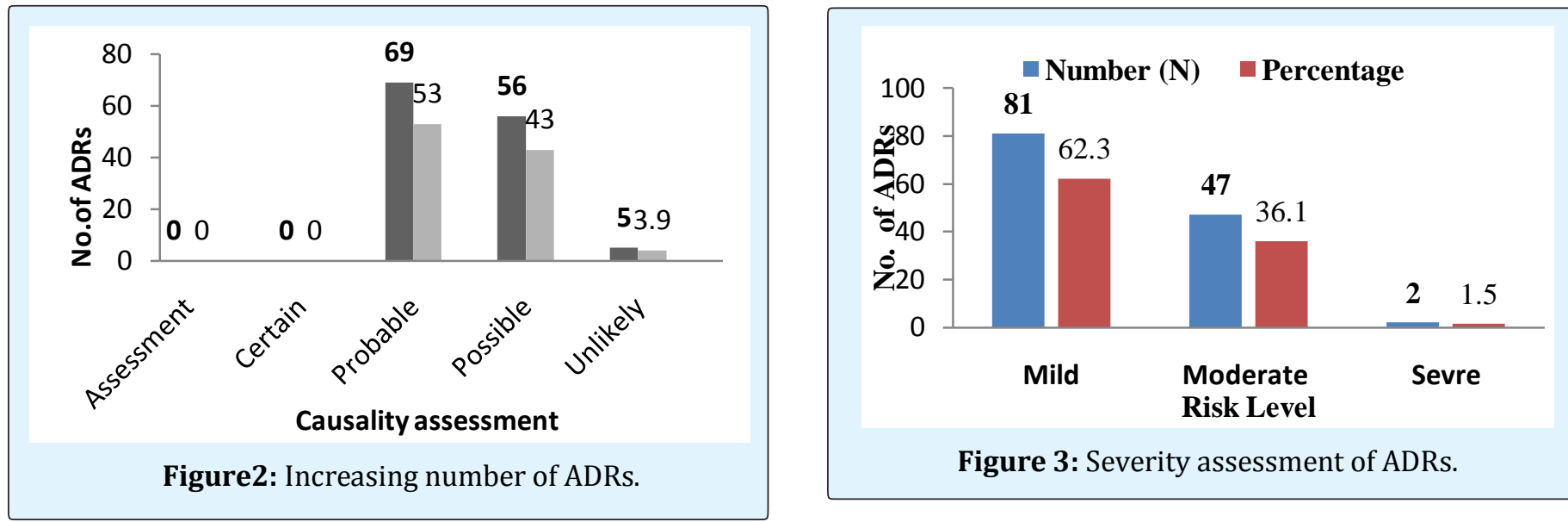

Figure 3: Severity assessment of ADRs.

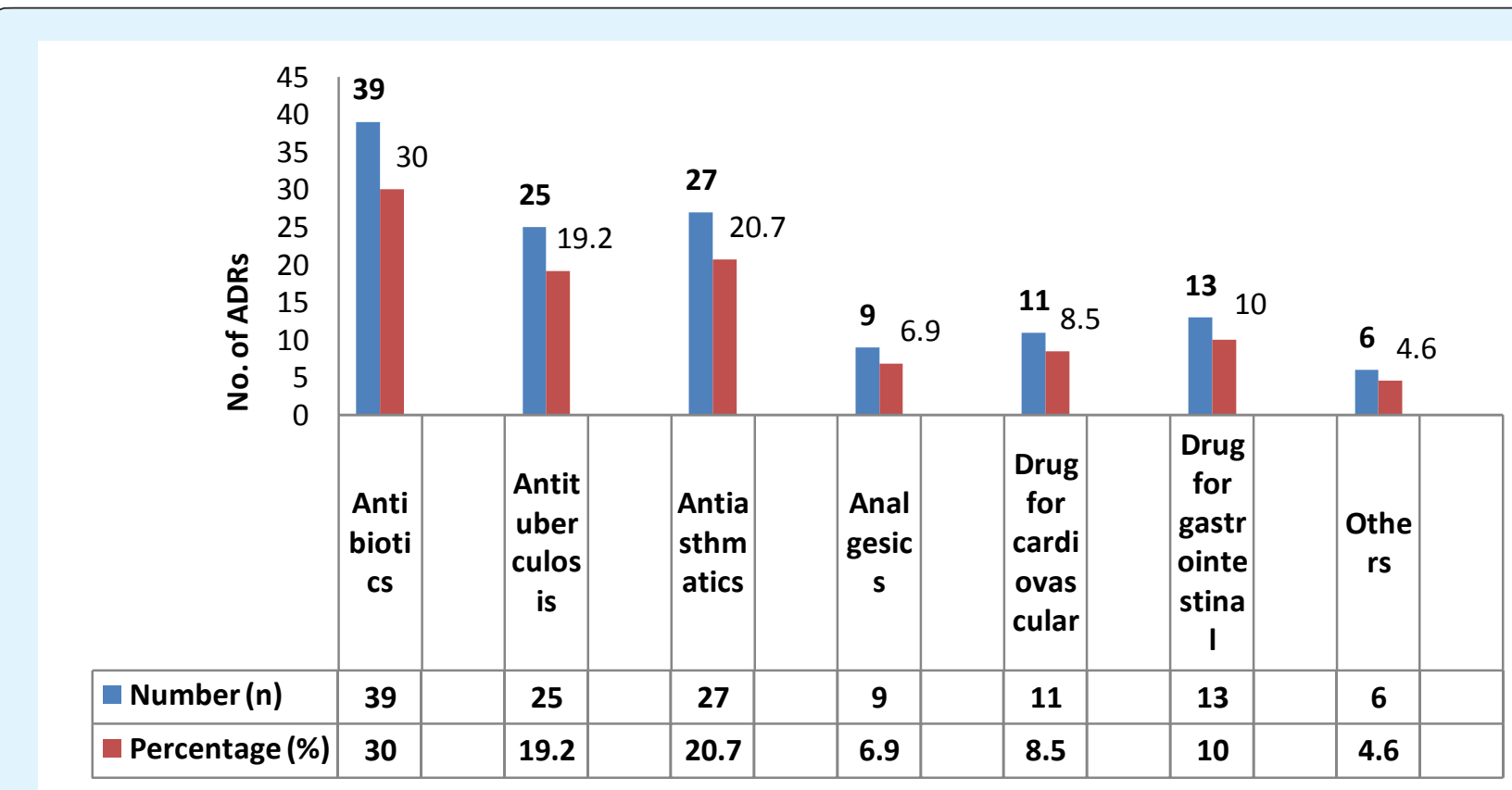

Figure 4: Suspected drugs, associated number of ADRs and percentage.

\section{Discussions}

A total 130 ADRs were reported in 6 months of the study was conducted in Respiratory medicine department at Chhatrapati Shivaji Subharti Hospital (Meerut) that is a 1038 bedded tertiary care teaching hospital in rural area. The data was collected by ADRs form in IPD and RICU department of the same. The age of the patients was 1590 years.

Among the 130 patients who got admitted due to respiratory ward, male $81(62.3 \%)$ were slightly more than female 49 (37.6\%) patients. Majority of the patients were from urban area 54 (41.5\%) followed by rural area $76(58.4 \%)$.

Total 130 ADRs were reported out of 130 patients who experienced the ADR of respiratory ward. The majority of cased of the adverse drug reactions were related to the skin reaction such as erythematous rash, urticaria and skin dryness 27 (20.7\%) cases, gastrointestinal reactions such as nausea, vomiting, gastritis and abdominal pain 22 (16.9\%), Central nervous system such as sedation, vertigo, severe headache and sleeping disturbance it happened in $29(22.3 \%)$ most of due to the first line anti- 


\section{Advances in Pharmacology and Clinical Trials}

tubercular drug like rifampicin, isoniazid, ethambutol and pyrazinamide and other drug like etizolam or FDC of furosemide+spironolactone, followed by cardiovascular such as palpitation and increased heart rate $4.6 \%$, eye, ears, nose, and throat symptoms 5 (3.9\%), hepatotoxicity 7 (5.3\%), general disorder such as fever, dehydration, pain and swelling at injection site.

However, the management of the ADRs occurrence respiratory patient were done with add-on therapy 14 $(10.8 \%)$, then followed by drug permanently withdrawn 87 (66.9\%), dose reduced 18 (13.8\%), frequency of dose schedule reduced $11(8.4 \%)$ cases.

The Causality of each ADR was assessed by using WHO-UMC causality assessment scale. On the basis of scale nearly 69 (53.0\%) ADRs were found to be probable while $56(43.0 \%)$ were possible and Unlikely 5 (3.9\%).

The severity assessment of the each ADR was assessed by the modified Hartwig and Siegel scale. Highest percentage of ADRs 81 (62.3\%) were classified as mild and $47(36.1 \%)$ were moderate and Severe $2(1.5 \%)$ on Hartwig and Siegel scale.

Most ADR was associated with Antibiotics 39 (30\%), followed antituberculosis 25 (19.2\%), antiasthmatics 27 (20.7\%), Analgesics 9 (6.9\%), drug for cardiovascular 11 (8.5\%), rug for gastrointestinal $13(10 \%)$ and others such as diuretics, $\beta$ - blockers, vitamins preparations etc. 6 (4.6\%).

\section{Conclusion}

The study is highlighted the need of ADR monitoring in patients receiving drug therapy for respiratory diseases. The treatment pattern of respiratory diseases in the tertiary care hospital indicates the presence of irrational use of drugs such as antiasthmatics, Antituberculosis, Antibiotics and other drugs prescription prevalence is high.

ADRs constitute a considerable burden of society both financially and in terms of human suffering, it can have a determinant effect on a patient's wellbeing and the overall health care system. Many time patients discontinue their treatment because of the suffering of the adverse drug reaction. Some time it may be very dangerous for the patient as well as society e.g. if the patient discontinue their Antitubercular treatment the risk of the failure of the tubercular treatment increased and it may be the chance of resistance tuberculosis. So now the time has come to aware the general public too for the reporting the adverse drug reaction to nearest hospital or ADR monitoring centre or to the healthcare professionals. They may directly report the ADR through govt. Toll-free number 18001803024, ADR application, email and other method like social media.

\section{References}

1. (2002) World Health Organization. The Importance of Pharmacovigilance, Safety Monitoring of medicinal products. World Health Organization 34-38.

2. Chen A, Kia NB, Usuba K (2018) Health-related quality of life in Canadians with asthma: A casecontrol study using census data. Respiratory medicine 140(6): 82-86.

3. Hyldgaard C, Bendstrup C, Pedersen AB, Ulrichsen SP, Lokke A, et al. (2018) Increased mortality among patients with rheumatoid arthritis and COPD: A population-based study. Respiratory medicine 140: 101-107.

4. Zhu Z, Hofauer B, Wirth M, Katrin Hasselbacher, Helmut Frohnhofen, et al. (2018) Selective upper airway stimulation in older patients. Respiratory medicine 140: 77-81.

5. WA Forest, Lopardo G, Wiemken TL, Kelley R4, Peyrani P, et al. (2018) Macrolide therapy is associated with lower mortality in communityacquired bacteraemic pneumonia. Respiratory medicine 140: 115-121.

6. Najafi S (2018) Importance of Pharmacovigilance and the Role of Healthcare Professionals. Journal of Pharmacovigilance 6(1): 1-2.

7. Almandil NB (2016) Healthcare professionals' awareness and knowledge of adverse drug reactions and pharmacovigilance. Saudi Med J 37(12): 13591364. 